\title{
PREDICTIVE ANALYTIC KLASIFIKASI PENENTUAN TARIF SEWA BUS
}

\author{
Nuqson Masykur Huda \\ School of Electric and \\ Informatics \\ Institut Teknologi Bandung \\ Bandung, Indonesia \\ nuqson@students.itb.ac.id
}

\author{
Arif Rachmat \\ School of Electric and \\ Informatics \\ Institut Teknologi Bandung \\ Bandung, Indonesia \\ aiepbug@students.itb.ac.id
}

\author{
Sri Anita \\ School of Electric and \\ Informatics \\ Institut Teknologi Bandung \\ Bandung, Indonesia \\ sri.anita@students.itb.ac.id
}

Currently, the bus rental business has become the choice of consumers in traveling, because of the decision of flexibility and better availability. The government regulates that consumer and business owner agreements determine bus rental rates without routes. In this study intends to do clustering from the history of raw data that already exists before. Data is obtained from companies in the form of spreadsheet files originating from non-information systems. The raw data is combined and normalized, to eliminate the noise data and the data is not abnormal. The clustering results using the K-Means algorithm and Louvain clustering produce several tariff groups that can be used as a reference for determining fare. In this paper also concludes about unbalanced data, which can cause data clustering errors.

Keywords_-predictive analytics, prediksi harga, tarif bus, K-Means, Louvain clustering.

\section{Pendahuluan}

Saat ini traveling telah menjadi gaya hidup dan merupakan kebutuhan bagi masyarakat di Indonesia, baik bagi kaum muda maupun orang tua. Motivasi setiap orang untuk traveling dapat berbeda-beda, mulai dari keluar dari rutinitas sehari-hari, istirahat dari penatnya pekerjaan, meredakan stres, mencari pengalaman baru, ataupun sekedar wisata kuliner. Hal tersebut memicu bisnis travel semakin menjamur di Indonesia. Tentunya biro wisata dalam menjalankan bisnis travel tidak dapat memenuhi semua layanan dari dirinya sendiri. Misalnya layanan transportasi, perusahaan biro wisata akan menggandeng perusahaan otobus untuk memenuhi layanan transportasi. Dari sisi kacamata bisnis layanan bus melayani kegiatan wisata mempunyai prospek cerah pada saat ini. Lebih dari itu, penggunaan bus tidak terbatas pada kegiatan wisata saja, penggunaan bus banyak juga dilakukan pada kegiatan kantor, seminar, kunjungan kelembagaan, wisata religi/ ziarah, serta tujuan perjalanan lainnya.

Terdapat beberapa kelebihan bus dibandingkan angkutan darat lainnya. Bus memiliki daya angkut yang lebih besar dibandingkan kendaraan jalan raya lainnya. Meningkatnya volume kendaraan saat ini yang tidak sebanding dengan kapasitas jalan, menumpuknya kendaraan dari luar kota pada saat akhir pekan, peralihan dari angkutan umum ke angkutan pribadi menjadi sebagian masalah pada pengelolaan transportasi di kota Bandu ng (Andrew B. Osmond, dkk., 2019). Sebuah bus yang mengangkut diperkirakan berpotensi mereduksi 55 mobil dari jalanan. Bahkan daya angkut bus lebih besar daripada monorel, jika monorel pada umumnya mampu mengangkut 90 penumpang, bus mampu mengangkut hingga 200 penumpang. Artinya, sebuah bus sebanding dengan dua gerbong monorel, sehingga penggunaan bus relatif lebih efektif dalam mengurangi kemacetan. Jalur yang digunakan bus sama dengan kendaraan lain dan dapat menjangkau banyak tujuan. Kelebihan lain bus dibandingkan dengan mobil adalah tarif yang lebih murah dihitung per orang. Tingkat keamanan Bus juga relatif lebih baik. Angka kematian akibat kecelakaan pada bus terbukti lebih kecil dibandingkan kendaraan seperti minibus atau sepeda motor.

Di tengah terpuruknya bisnis angkutan trayek yang kalah dengan penyedia layanan transportasi daring, penyewaan bus masih memiliki prospek cerah. Seperti dalam artikel 
(Suherni, 2017), PO Bluebird lebih mengembangkan bus pariwisata dibandingkan taksi yang mengalami masa sulit akibat tergusur dengan layanan transportasi daring. Sementara ini belum ada layanan daring yang menggusur bus pariwisata. Akan tetapi, meskipun bisnis jasa sewa bus masih menjanjikan namun perang harga di antara penyedia jasa sewa bus terus meningkat. Tentunya dengan permintaan yang masih tinggi kompetisi harga di antara perusahaan otobus juga semakin meningkat.

Tarif merupakan komponen penting yang menjadi pertimbangan pelanggan dalam memilih bus pariwisata. Untuk menentukan tarif dari sebuah layanan banyak metode yang dapat digunakan baik dari sisi ekonomi maupun lainnya. Penelitian ini mencoba melakukan predictive analytic untuk menentukan tarif dengan menentukan klasifikasi tingkat tarif dengan memanfaatkan data riwayat transaksi pada PO Grand Star Holidays. Diharapkan dengan analisis atribut pada data transaksi dapat menentukan tarif bus di perusahaan.

\section{A. Profil PO. Grand Star Holidays}

Salah satu perusahaan otobus yang berlokasi di Bandung adalah PO. Grand Star Holidays yang bergerak dibidang jasa transportasi penyewaan bus. Perusahaan ini menjalankan bisnis utama penyewaan bus dan minibus. PO Grand Star Holidays tidak menjalankan rute atau trayek tertentu, perusahaan tersebut hanya melayani penyewaan berdasarkan hari. Perhitungan tarif didasarkan pada berapa lama sewa Bus yang dihitung per hari. Tarif sewa sudah termasuk jasa kru bus dan bahan bakar, kemudian untuk biaya beban yang lain, seperti retribusi parkir tol dana lainnya menjadi tanggungan penyewa. Rata-rata pelanggan dari PO Grand Star Holidays adalah biro perjalanan dan event organizer, namun banyak juga dari sekolah dan instansi di sekitar Bandung.

\section{B. Stake Holder Bisnis Jasa Penyewaan Bus}

Penentuan tarif sangat terkait dengan pelanggan dan kompetitor. Hal ini sesuai dengan prinsip demand and supply dari penyedia jasa transportasi. Stakeholder lain dari dari jasa transportasi darat dalam hal ini jasa penyewaan bus adalah organda. Setiap perusahaan otobus wajib tergabung dengan asosiasi atau perkumpulan penyedia jasa transportasi darat atau dikenal dengan organda. Organda merupakan kepanjangan dari organisasi angkutan darat. Organda adalah organisasi resmi yang dibentuk pemerintah tahun 1963 melalui Surat Keputusan Menteri Perhubungan Darat, Pos, Telekomunikasi dan Pariwisata Nomor L. 25/1/18/1963 tanggal 17 Juni 1963. Organda merupakan organisasi tunggal dalam bidang angkutan bermotor di jalan raya. Untuk meningkatkan pelayanan kepada masyarakat, organda mengeluarkan beberapa aturan dan SOP terkait angkutan orang darat yang harus dipatuhi oleh semua anggota.

Pemerintah merupakan salah satu stakeholder dalam bisnis jasa transportasi. Pemerintah melalui Kementerian Perhubungan dan Dinas Perhubungan juga mengeluarkan beberapa aturan untuk menjamin keamanan, keselamatan dan kenyamanan pengguna jasa transportasi darat.

\section{Stake Holder Bisnis Jasa Penyewaan Bus}

Tarif secara legalitas untuk sewa bus pariwisata tidak ada campur tangan dengan pemerintah dalam hal ini dinas perhubungan. Berbeda dengan bus yang memiliki trayek atau jalur tetap, setiap tarif harus didiskusikan dengan pihak dinas perhubungan dan organda. Namun meski tidak menentukan tarif secara langsung namun setiap perusahaan otobus wajib terdaftar dan mematuhi semua aturan yang ada dalam organda. Pemerintah telah berupaya untuk mengelola jasa transportasi darat di Indonesia. Sebagai bentuk perlindungan konsumen pemerintah telah mengeluarkan beberapa aturan mengenai KIR, standar keselamatan penumpang dan aturan lain yang mendukung kenyamanan penumpang. Saat ini memang belum ada aturan yang mengikat dan mengatur tentang tarif pada bus non trayek. 
Sesuai peraturan Bus wisata bisa masuk angkutan umum non trayek. Bus atau kendaraan wisata yang dioperasikan harus laik jalan, dibuktikan dengan uji kir berkala. SDM yang mengoperasikan kompeten, dibuktikan dengan SIM resmi sesuai jenis dan kategori kendaraan yang dikemudikan. Pemerintah telah yang mengatur layanan jasa transportasi penyewaan bus non trayek lewat Peraturan Menteri Perhubungan No. 108 tahun 2017 tentang Penyelenggaraan angkutan orang dengan kendaraan bermotor umum tidak dalam trayek yakni angkutan dalam wilayah perkotaan dan/atau kawasan tertentu, atau dari suatu tempat ke tempat lain, mempunyai asal dan tujuan tetapi tidak mempunyai lintasan dan waktu tetap. Beberapa jenis angkutan yang termasuk dalam kategori di atas yaitu taksi, angkutan pariwisata, angkutan karyawan, angkutan sewa, angkutan permukiman, dan angkutan sewa khusus dengan penggunaan aplikasi berbasis teknologi informasi. Pada pasal 104 menyebutkan tarif penumpang untuk angkutan orang tidak dalam trayek dengan tujuan tertentu, pariwisata, dan di kawasan tertentu sebagaimana dimaksud dalam Pasal 102 huruf $b$ ditetapkan berdasarkan kesepakatan antara pengguna jasa dan perusahaan angkutan umum. Peraturan terkait dengan angkutan bus non trayek :

i. $\quad$ Undang-Undang Nomor 22 Tahun 2009 tentang Lalu Lintas dan Angkutan Jalan

ii. Undang-undang Nomor 14 Tahun 1992 tentang Lalu Lintas dan Angkutan Jalan

iii. Peraturan Pemerintah Nomor 32 Tahun 2011 tentang Manajemen dan Rekayasa, Analisis Dampak, serta Manajemen Kebutuhan Lalu Lintas

iv. Peraturan Pemerintah Republik Indonesia Nomor 74 Tahun 2014 Tentang Angkutan Jalan

v. Peraturan Menteri Perhubungan Republik Indonesia Nomor PM 108 tahun 2017 tentang Penyelenggaraan Angkutan Orang Dengan Kendaraan Bermotor Umum Tidak Dalam Trayek

vi. Keputusan Menteri Perhubungan Nomor KM. 35 Tahun 2003 tentang Penyelenggaraan Angkutan Orang di jalan.

\section{Rumusan Masalah}

Penentuan tarif seharusnya tidak hanya dilakukan berdasarkan perkiraan saja, tetapi dengan berdasarkan perhitungan tarif yang benar. Apabila tarif terlalu tinggi, maka berakibat pindahnya konsumen ke perusahaan lain yang lebih murah. Tetapi, apabila tarif yang ditetapkan terlalu rendah maka berdampak pada kelangsungan operasional perusahaan. Perusahaan menjadi rugi dan dalam jangka panjang akan tidak menguntungkan perusahaan. Maka dari itu, diperlukan manajemen yang dapat menentukan strategi dan kebijakan penetapan harga yang tepat. Standarisasi tarif yang berlaku pada masing-masing perusahaan mempunyai relevansi yang akan dapat membawa kemajuan perusahaan.

Tarif yang telah disepakati oleh konsumen dan perusahaan akan membawa dampak yang cukup baik bagi kelancaraan perusahaan. Pada dasarnya dalam keadaan normal harga jual produk atau jasa harus dapat menutup biaya penuh perusahaan baik biaya langsung atau tidak langsung. Pengertian biaya penuh adalah total pengorbanan sumber ekonomi untuk menghasilkan produk atau jasa terjadi penurunan jumlah konsumen.

\section{Rancangan Solusi}

Pada penelitian ini penulis ingin mengusulkan klasifikasi tarif baru dan menganalisis besar tarif sudah tepat atau belum. Oleh karena itu, penulis mengusulkan clustering tarif berdasarkan jarak dan biaya beban yang dikeluarkan. Proses clustering dengan memanfaatkan data transaksi dengan mengambil atribut jarak perjalanan dan biaya beban yang dikeluarkan selama dalam perjalanan. Setelah mendapatkan kelas yang sesuai dengan yang parameter yang telah ditetapkan pada selanjutnya usulan clustering tersebut dianalisa apakah tarif yang telah digunakan selama ini lebih menguntungkan atau tidak dibandingkan dengan kelas yang sudah dibentuk. 


\section{A. Teknik Clustering}

Teknik klasifikasi yang digunakan dalam penelitian ini adalah unsupervised machine learning. Data yang digunakan belum ada label. Dari sebaran data yang sudah ada dibangun model untuk memetakan cluster atau kelas dengan parameter tertentu. Hasil dari pemetaan sebaran kelas tersebut di gunakan untuk menentukan kelas.

\section{B. Algoritma}

Algoritma yang digunakan dalam membuat model pada penelitian ini menggunakan tiga jenis algoritma. Dari masing-masing algoritma tersebut dibandingkan seberapa bagus kelas yang terbentuk dari masing-masing algoritma. Ketiga algortima tersebut adalah K-Mean, LDS, dan Louvian Clustering.

\section{1) Louvain Clustering}

Louvain clustering adalah metode untuk mendeteksi komunitas dalam jaringan. Metode salah satu jenis unsupervised learning yang memaksimalkan bobot sebaran untuk setiap komunitas, di mana sebaran menjumlahkan kualitas bobot node ke komunitas dengan mengevaluasi seberapa jauh lebih padat node yang terhubung dalam suatu komunitas, dibandingkan dengan seberapa terhubung mereka dalam jaringan acak. (Blondel dkk., 2008).

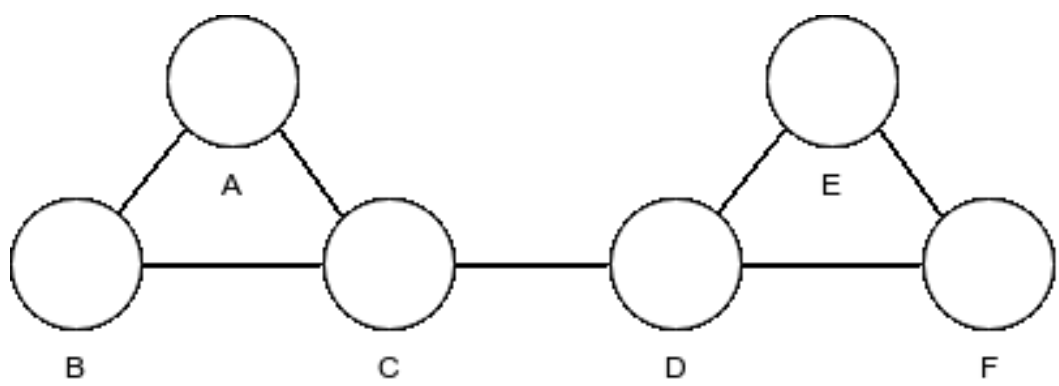

Figure 1. Ilustrasi relasi pada algoritma louvain clustering

\section{2) K-Means}

K-Means adalah suatu metode dalam menganalisa data dan merupakan salah satu metode yang melakukan pengelompokan data dengan sistem partisi. Metode k-means berusaha mengelompokkan data yang ada ke dalam beberapa kelompok, di mana data dalam satu kelompok mempunyai karakteristik yang sama satu sama lainnya dan mempunyai karakteristik yang berbeda dengan data yang ada di dalam kelompok yang lain. Dengan kata lain, metode ini berusaha untuk meminimalkan variasi antar data yang ada di dalam suatu cluster dan memaksimalkan variasi dengan data yang ada di cluster lainnya. (McCall dkk., 2002). 


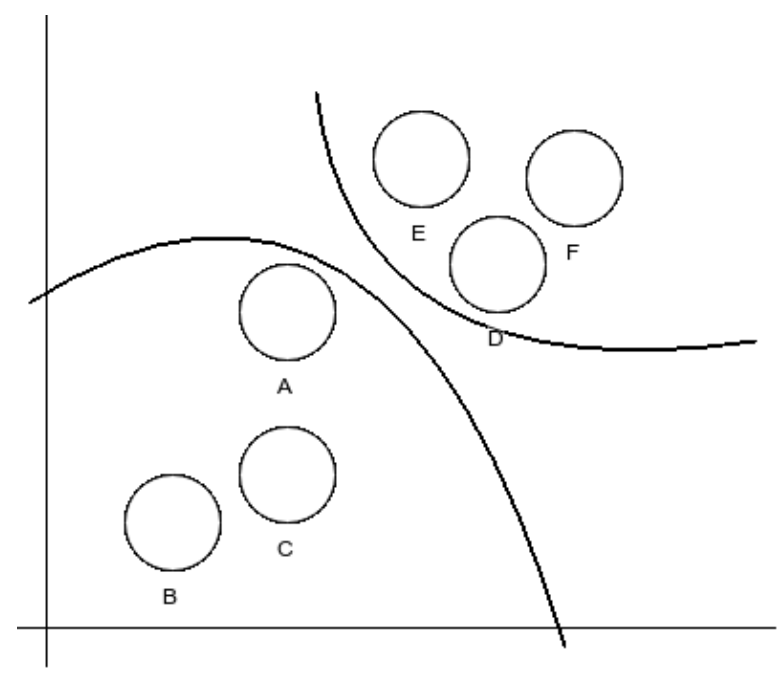

Figure 2. Ilustrasi relasi pada algoritma k-Means

\section{Tingkat Kelas}

Penetapan tarif merupakan salah satu keputusan tersulit yang dihadapi oleh perusahaan, karena penetapan tarif merupakan hal yang cukup fatal di dalam kebijaksanaan manajemen. Jika manajemen salah dalam menentukan tarif maka kemungkinan besar yang teIjadi adalah pangsa pasar perusahaan akan berkurang bahkan semakin menjauh. Oleh karena itu dibutuhkan ketepatan di dalam hal penetapan tarif. Prosedur-prosedur untuk menentukan tarif sewa bis pariwisata menurut metode pendekatan biaya dan pendekatan pasar sebagai berikut

i. Membuat taksiran biaya-biaya yang akan teIjadi dalam satu tahun.

ii. Memisahkan taksiran biaya ke dalam biaya produksi dan non produksi, kemudian menghitung total biaya produksi dan non produksi untuk mendapatkan biaya penuh untuk setiap jenis bis.

iii. Menentukan laba yang diharapakan.

iv. Menghitung persentase mark-up yang diperoleh dari biaya non produksi ditambah dengan laba diharapkan dibagi dengan biaya produksi dan dikali 100\%.

Dari perhitungan tersebut di tetapkan oleh perusahaan bahwa laba yang diharapkan sebanyak $30 \%$ dari total pengeluaran. Sedangkan biaya non produksi s ebesar $20 \%$ maka ditetapkan markup sebagai berikut :

Markup $=$ Keuntungan yang diharapkan + biaya penyusutan dan maintenance

Markup $=30 \%+20 \%$

Markup $=50 \%$ 


\section{Pengumpulan Data}

\section{A. Teknik pengumpulan dan deskripsi data}

Pencatatan dan pembukuan aktivitas bisnis pada Po Star Holidays secara elektronik baru mulai dilakukan pada Januari tahun 2018. Karena menurut pihak perusahaan, armada yang dipunyai masih sedikit dan masih dapat di tangani secara manual, pencatatan pun mas ih menggunakan buku. Selain alasan terebut, belum ada petugas yang fasih dan mampu mengoperasikan komputer dengan baik. Baru pada tahun 2018 pihak perusahaan merekrut staf yang sudah berpengalaman pada pembukuan dan dapat mengoperasikan komputer.

Data yang dihimpun dalam penelitian ini adalah rekaman data dalam bentuk spreadsheet dari tahun 2018 sampai tahun 2019. Data di dapat dengan survei lapangan, wawancara dengan pemilik dan admin pembukuan. Untuk data aktivitas dan pembukuan perusahaan di dapatkan secara langsung dari admin berupa file spreadsheet. Data yang didapat berupa : data detail setiap transaksi, data rekapan bulanan, data sopir dan karyawan, data kelengkapan bus, dan data unit bus. Data yang didapat mulai 1 Januari 2018 sampai 31 desember 2018 dengan jumlah record transaksi sebanyak 583. Berikut deskripsi data yang didapatkan :

Tabel 1.Table data transaksi, total 583 record.

\begin{tabular}{|c|c|c|}
\hline Nama field & Tipe (panjang) & Keterangan \\
\hline Nomor surat jalan & String (30) & Key ide (unique) \\
\hline Tanggal dan jam berangkat & Datetime & \\
\hline Jumlah hari sewa & $\operatorname{int}(5)$ & \\
\hline Tanggal dan jam kembali & Datetime & \\
\hline Nama Customer & String (30) & \\
\hline Phone customer & String $(15)$ & \\
\hline Alamt jemput & String(50) & \\
\hline Tujuan & String $(50)$ & \\
\hline Driver -1 & String $(20)$ & \\
\hline Co driver & String(20) & \\
\hline NO.Body & String $(10)$ & \\
\hline Pengeluaran IDE & $\operatorname{Int}(20)$ & \\
\hline Upah driver & $\operatorname{Int}(20)$ & \\
\hline Upah codriver & $\operatorname{Int}(20)$ & \\
\hline Biaya lain & $\operatorname{Int}(20)$ & \\
\hline Uang makan & $\operatorname{Int}(20)$ & \\
\hline Total uang jalan & $\operatorname{Int}(20)$ & \\
\hline Setoran sewa & $\operatorname{Int}(20)$ & \\
\hline Ket & String (50) & \\
\hline
\end{tabular}

Tabel 2.Table data rekap bulanan, total 12 record

\begin{tabular}{|c|c|c|}
\hline Nama field & Tipe (panjang) & Keterangan \\
\hline Nomor surat jalan & String (30) & Key ide (unique) \\
\hline Tgl berangkat & Date & \\
\hline Setoran & Int $(20)$ & \\
\hline Uang jalan & Int $(20)$ & \\
\hline Ket & String (50) & \\
\hline
\end{tabular}

Tabel 3.Table data sopir dan karyawan, total 20 record

\begin{tabular}{|c|c|c|}
\hline Nama field & Tipe (panjang) & Keterangan \\
\hline
\end{tabular}




\begin{tabular}{|c|c|c|}
\hline Nama & String (30) & Key ide (unique) \\
\hline Ide. HP & String (15) & \\
\hline Alamat & String(50) & \\
\hline Status & String(10) & \\
\hline Ket & String (50) & \\
\hline
\end{tabular}

Tabel 4.Table data unit bus, total 7 record

\begin{tabular}{|c|c|c|}
\hline Nama field & Tipe (panjang) & Keterangan \\
\hline NO BODY & String (10) & \\
\hline PLAT NO & String (9) & \\
\hline NO RANGique) \\
\hline NO MESIN & String(20) & \\
\hline TIPE BUS & String(20) & \\
\hline TAHUN & String (50) & \\
\hline KAPASITAS & Year & \\
\hline Type/ MERK & Int $(5)$ & \\
\hline
\end{tabular}

Tabel 5.Table data kelengkapan bus, total 7 record

\begin{tabular}{|c|c|c|}
\hline Nama field & Tipe (panjang) & Keterangan \\
\hline No Body & String (10) & \\
\hline Jenis Perlengkapan & String (50) & \\
\hline Macam Audio Video & String(50) & \\
\hline Jumlah & int(5) & \\
\hline Type/ Merk & String (50) & \\
\hline Kondisi & String(10) \\
\hline
\end{tabular}

\section{B. Pre-Processing}

Dari data yang telah dikumpulkan selanjutnya dilakukan tahap pre-processing agar data dapat dilakukan proses learning. Dalam penelitian ini karena yang dicari adalah keterhubungan tarif maka tabel yang digunakan adalah tabel transaksi. Selanjutnya disiapkan tabel beru dengan atribut sebagai berikut :

Tabel 5.Table data kelengkapan bus, total 7 record

\begin{tabular}{|c|c|c|}
\hline Nama field & Tipe (panjang) & Keterangan \\
\hline No & int (5) & Key ide (unique) \\
\hline Jarak & int $(10)$ & \\
\hline Biaya beban & Int $(20)$ & \\
\hline
\end{tabular}

Data dari tabel awal data transaksi di load ke dalam tabel baru sesuai atribut yang akan digunakan. Untuk mengisi kolom jarak tempuh, pengisian data dilakukan dengan memanfaatkan api dari google map dengan inputan tempat jemput dan tujuan. Meskipun tidak dapat menggambarkan secara nyata berapa jarak perjalanan yang ditempuh, namun didapatkan perkiraan berapa km perjalanan selama bus disewa. Perhitungan jarak tempuh dapat dihitung dengan rumus sebagai berikut :

$$
\mathbf{J T}=(\mathbf{J T} \mathbf{J}+\mathbf{J G J}) \times 2
$$

JT : jarak tempuh

JTJ : jarak antara titik jemput sampai tujuan

JGJ : Jarak dari garasi/pool sampai titik jemput 


\section{Analisis Deskriptif}

Hasil akhir diharapkan ada pemetaan tingkat tarif yang dihasilkan dari clustring yang dilakukan. Hasil clustering diharapkan dapat menjadi bahan pertimbangan bagi pemilik usaha dalam menentukan tarif yang terbaik tanpa merugikan dari sisi pemilik usaha maupun pelanggan. Berdasarkan dataset yang telah dimiliki, maka akan dilakukan analisa data yang telah ada dengan menggunakan beberapa fitur yang sekiranya dapat menjadi parameter utilize dari setiap unit kendaraan seperti harga sewa perhari, biaya fee driver, biaya fee co-driver, ongkos bahan bakar, titik awal, titik tujuan, jarak tempuh, unit bus. Fitur tersebut diproyeksikan sebagai parameter yang bisa memberikan insight dalam penentuan tarif selanjutnya.

\section{EKSPERIMEN DAN HASIL}

Pada bagian ini menjelaskan tentang tahapan dalam melakukan analisis data, setelah raw data yang diperoleh dilakukan pre-processing, maka dilanjutkan dengan proses pembuatan model dengan menggunakan algoritma yang telah didefinikan sebelumnya.

\section{A. Analisis data}

Penelitian ini menggunakan perangkat lunak data mining bernama "orange". Langkah pertama adalah menyiapkan data yang tadi sudah melewati tahap pre-processing. Berdasarkan hasil clustering dan perubahan peubah berapa kelas yang akan dibuat, jika terlalu banyak kelas maka harga cenderung membingungkan pelanggan, jika kelas terlalu sedikit kelas yang ditentukan maka tujuan awal pengkategorian agar tarif sesuai dengan beban dan jarak tidak tercapai dengan baik.

\section{B. Analisis data}

Dengan menggunakan rumus yang telah didefinisikan pada bagian sebelumnya, maka dapat didefinisikan tarif :

Markup $=$ Keuntungan yang diharapkan + biaya penyusutan dan servic e

Markup $=30 \%+20 \%$

Mark up $=50 \%$

Tarif $=150 \% \mathrm{x}$ rentang pengeluaran

Selanjutnya akan dilakukan analisa terhadap data, dengan langkah-langkah sebagai berikut :

i. Normalisasi data yakni menyalin raw data spreadsheet dari pemilik usaha, karena data yang diberikan belum berupa record seperti umumnya database.

ii. Penyeleksian fitur, dari sekian banyak fitur yang terdapat pada data, pada penelitian ini memilih fitur signifikan yang dianggap mempengaruhi model tarif yang akan diusulkan yakni jarak tempuh, total biaya pengeluaran, jumlah hari, dan jumlah pemasukan.

iii. Penghapusan noise data, dalam data yang telah dinormalisasi masih terdapat noise seperti data perjalanan yang batal namun tidak terhapus dalam database, data perjalanan yang jumlah pengeluarannya nol rupiah.

iv. Load dataset, yakni melakukan pengambilan data yang dianggap telah bebas noise untuk diberikan parameter bagi tiap-tiap kolom data, yakni numerik, teks dan meta. Karena metode yang digunakan adalah clustering maka tidak ada pemberian paramaeter target pada data.

v. Building model, langkah ini adalah melakukan proses clustering dari dataset dengan menggunakan algoritma yang ada. 
vi. Save model, setelah proses clustering selesai maka hasilnya disimpan menjadi sebuah model.

vii. Hasil cluster, model yang telah didefinisikan telah membentuk cluster yang akan menjadi dasar penentuan tarif.

\section{Evaluasi Model}

Algoritma K-Means, kelas yang dibentuk sebanyak 4 kelas. Hasil analisa dari peta sebaran titik disimpulkan berapa kelas yang akan dibentuk maka dapat disimpulkan bahw a sebaran dan frekuensi yang sering terjadi ditentukan 4 kelas dengan pertimbangan jarak dekat, jarak menengah, jarak jauh dan perjalanan dalam kota (city tour).

i. $\quad$ Kelas pertama dengan rentang pengeluaran $=300.000-1.270 .000$

Rentang jarak $=0 \mathrm{~km}-200 \mathrm{~km}$

Jumlah hari $=1$

Harga tarif $=450.000-1.905 .000$

ii. Kelas kedua dengan rentang pengeluaran $=1.270 .000-2.800 .000$

Rentang jarak $=93 \mathrm{~km}-471 \mathrm{Km}$

Jumlah hari $=1-3$

Harga tarif $=1.905 .000-4.200 .000$

iii. Kelas ketiga dengan rentang pengeluaran $=2.900 .000-6.800 .000$

Rentang jarak $=140 \mathrm{~km}-880 \mathrm{~km}$

Jumlah hari $=3-6$

Harga tarif $=4.200 .000-10.200 .000$

iv. Kelas keempat dengan rentang pengeluaran $=6.800 .000-10.000 .000$

Rentang jarak $=848-1180 \mathrm{~km}$

Jumlah hari $=5-10$

Harga tarif $=10.200 .000-15.000 .000$

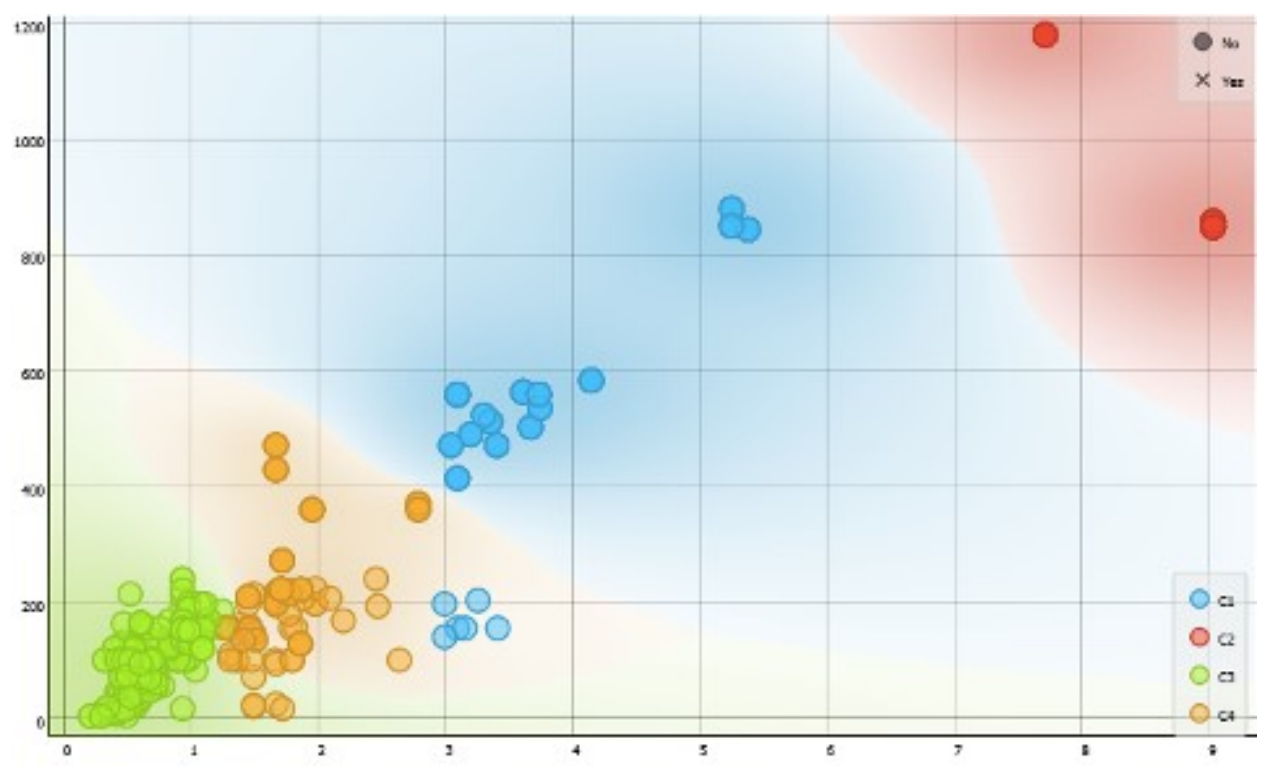

Figure 3. Hasil clustering menggunakan algoritma k-Means berdasarkan jarak 


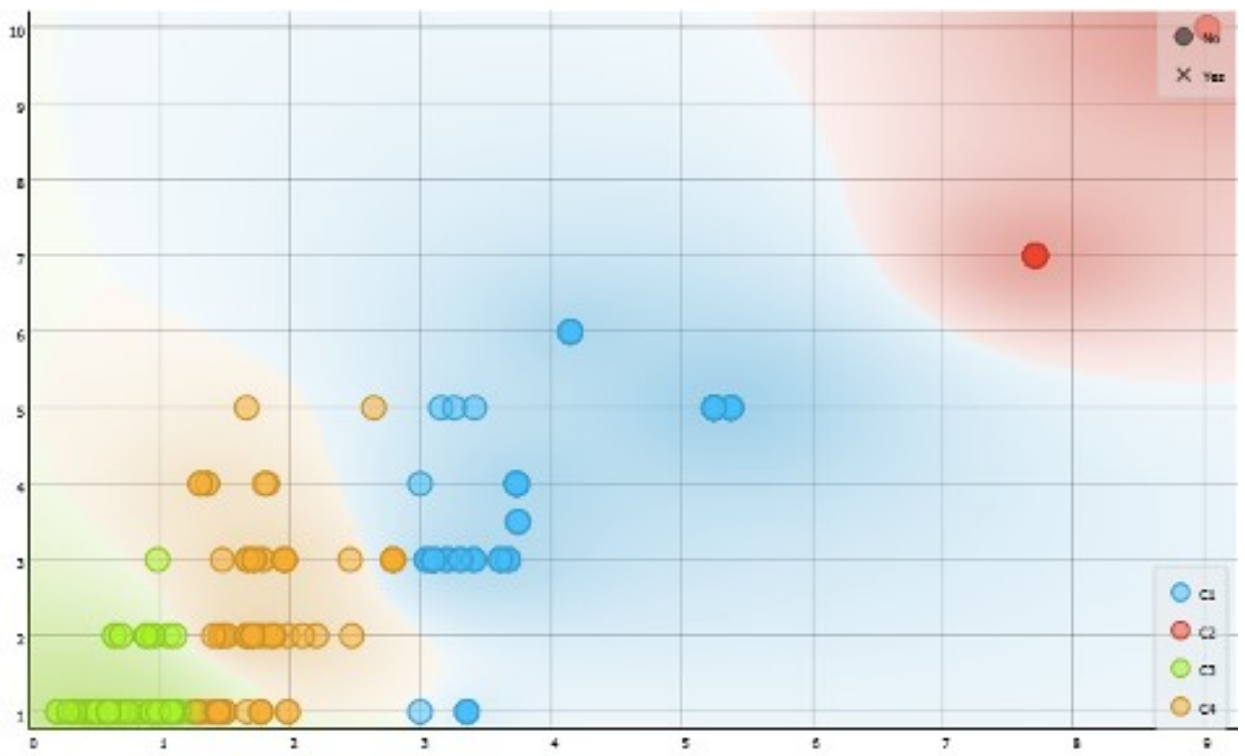

Figure 4. Hasil clustering menggunakan algoritma k-Means berdasarkan hari

Algoritma lovain clustering, metode ini akan menyusun kelas secara otomatis dengan mengatur berapa jumlah ke-tetangga-nnya. fituryang ditetapkan adalah 3 yaitu jarak, pengeluaran dan hari. $\mathrm{N}$ ketetangganan $=30$. Penggunaan algoritma Louvain Clustering menyusun kelas berdasarkan pemilihan atribut yang paling relevan. Dalam kasus ini metode louvain menggunakan fitur pengeluaran. Jadi dalam membangun kelas didasarkan pada fitur pengeluaran. Dari hasil learning data di peroleh sebaran sebagai berikut :

i. Kelas 1 dengan rentang pengeluaran $=220.000-560.500$

Rentang jarak $=0 \mathrm{~km}-160 \mathrm{~km}$

jumlah hari $=1$

Harga tarif $=330.000-840.750$

ii. Kelas 2 dengan rentang pengeluaran $=580.500-941.000$

Rentang jarak $=23 \mathrm{~km}-165 \mathrm{KM}$

Jumlah hari $=1-2$

Harga tarif $=870.750-1.411 .500$

iii. Kelas 3 dengan rentang pengeluaran $=838.000-966.750$

Rentang jarak $=100 \mathrm{~km}-240 \mathrm{~km}$

Jumlah hari $=1-2$

Harga tarif $=1.257 .000-1.450 .125$

iv. Kelas 4 dengan rentang pengeluaran $=992.250-1.250 .000$

Rentang jarak $=82-198$

Jumlah hari $=1-3$

Harga tarif $=1.488 .375-1.875 .000$

v. Kelas 5 dengan rentang pengeluaran $=1.291 .000-1.518 .500$

Rentang jarak $=100-214$

Jumlah hari $=1-4$

Harga tarif $=1.936 .500-2.277 .000$

vi. Kelas 6 dengan rentang pengeluaran $=1.676 .000-2.476 .000$

Rentang jarak $=100-272$

Jumlah hari $=1-5$

Harga tarif $=2.514 .000-3.714 .000$

vii. Kelas 7 dengan rentang pengeluaran $=2.645 .000-3.410 .000$

Rentang jarak $=140-558$ 
Jumlah hari $=1-5$

Harga tarif $=3.967 .500-5.115 .000$

viii. Kelas ke 8 dengan rentang pengeluaran $=3.616 .500-4.152 .500$

Rentang jarak $=502-583$

Jumlah hari $=1-6$

Harga tarif $=5.424 .750-6.228 .750$

ix. Kelas 9 dengan rentang pengeluaran $=5.255 .000-5.383 .000$

Rentang jarak $=840-880$

Jumlah hari $=1-5$

Harga tarif $=7.882 .500-8.077 .500$

x. Kelas 10 dengan rentang pengeluaran $=7.717 .500-9.037 .000$

Rentang jarak $=848-1180$

Jumlah hari $=7-10$

Harga tarif $=11.576 .250-13.555 .500$

xi. Kelas 11 dengan rentang pengeluaran diatas 9.050.000

Rentang jarak $=$ diatas 1200

Jumlah hari $=$ diatas 10

Harga tarif $=13.575 .000$

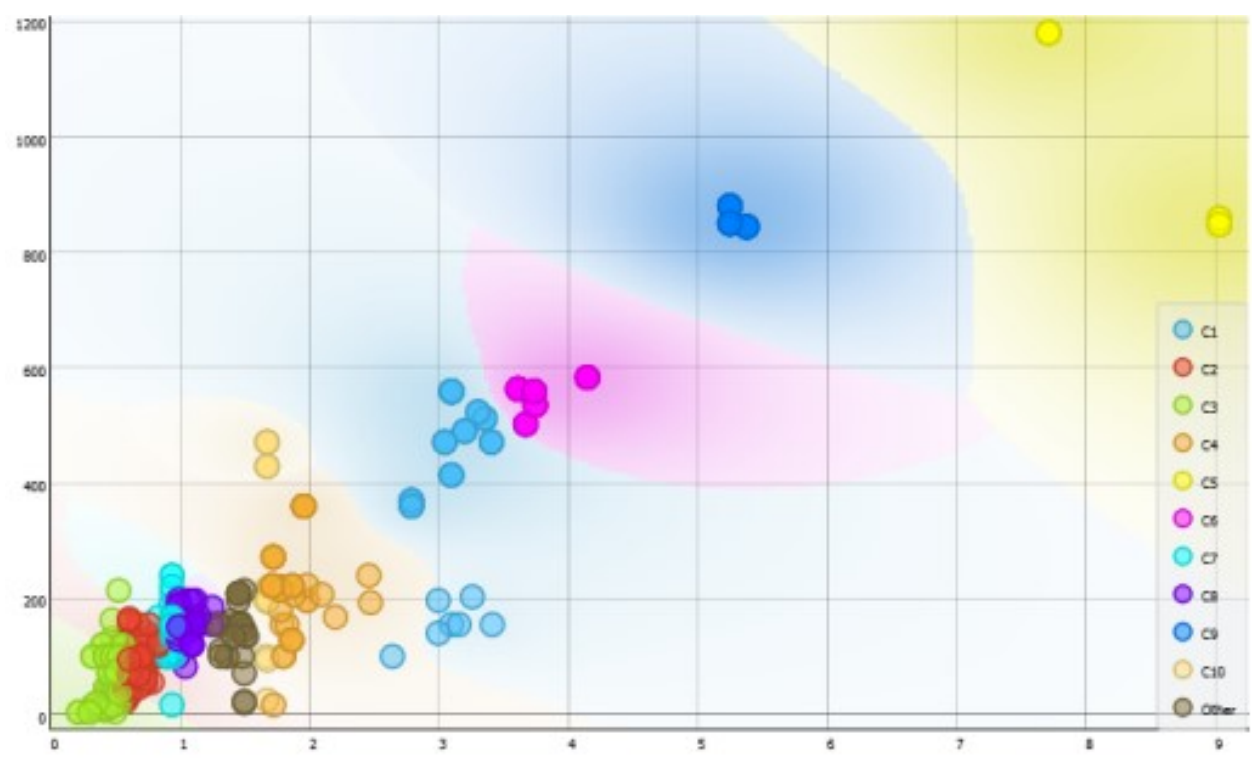

Figure 5. Sebaran cluster dengan feature pemasukan dan jarak menggunakan methode lovain 


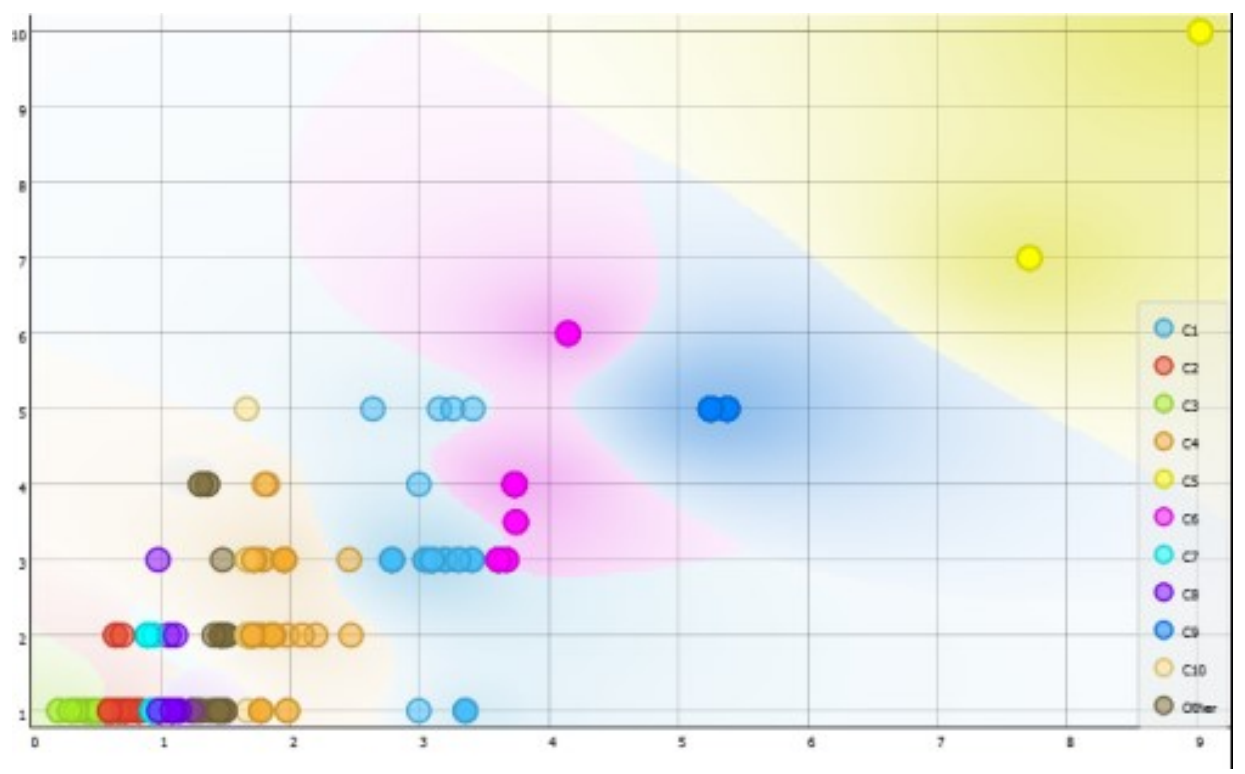

Figure 6. Sebaran cluster dengan feature pemasukan dan jumlah hari menggunakan metode lovain clustering

\section{Analisa Harga}

Hasil analisa perhitungan dengan clustering $\mathrm{K}$ means dan louvain, maka didapatkan nilai sebagi berikut :

Tabel 6.Analisa harga berdasarkan K-means

\begin{tabular}{|c|c|c|c|c|c|c|c|}
\hline Kelas & \multicolumn{2}{|c|}{ Rentang harga } & Mean harga & \multicolumn{2}{c|}{$\begin{array}{c}\text { Rentang } \\
\text { jumlah hari }\end{array}$} & $\begin{array}{c}\text { Mean } \\
\text { hari }\end{array}$ & $\begin{array}{c}\text { Tarif } \\
\text { perhari }\end{array}$ \\
\hline 1 & 450,000 & $1,905,000$ & $1,177,500$ & 1 & 1 & 1.5 & 785,000 \\
\hline 2 & $1,905,000$ & $4,200,000$ & $3,052,500$ & 1 & 3 & 3.5 & 872,143 \\
\hline 3 & $4,200,000$ & $10,200,000$ & $7,200,000$ & 3 & 6 & 7.5 & 960,000 \\
\hline 4 & $10,200,000$ & $15,000,000$ & $12,600,000$ & 5 & 10 & 13.5 & $1,008,000$ \\
\hline
\end{tabular}

dari usulan tersebut, maka didapatkan tarif yang diusulkan sebagai berikut :

Tabel 7.Usulan harga berdasarkan K-means

\begin{tabular}{|c|c|c|}
\hline Kelas & Range jarak & Tarif perhari \\
\hline 1 & $0 \mathrm{~km}-147 \mathrm{~km}$ & 785,000 \\
\hline 2 & $147 \mathrm{~km}-306 \mathrm{Km}$ & 872,143 \\
\hline 3 & $306 \mathrm{~km}-863 \mathrm{~km}$ & 960,000 \\
\hline 4 & $863 \mathrm{~km}-1180 \mathrm{~km}-\mathrm{dst}$ & $1,008,000$ \\
\hline
\end{tabular}


Tabel 8.Analisa harga berdasarkan Louvain clustering

\begin{tabular}{|c|c|c|c|c|c|c|c|}
\hline Kelas & \multicolumn{2}{|c|}{ Rentang harga } & Mean harga & \multicolumn{2}{c|}{$\begin{array}{c}\text { Rentang jumlah } \\
\text { hari }\end{array}$} & $\begin{array}{c}\text { Mean } \\
\text { hari }\end{array}$ & $\begin{array}{c}\text { tarif } \\
\text { perhari }\end{array}$ \\
\hline 1 & 220,000 & 560,500 & 390,250 & 1 & 1 & 1.5 & 260,167 \\
\hline 2 & 580,500 & 941,000 & 760,750 & 1 & 2 & 2.5 & 304,300 \\
\hline 3 & 838,000 & 966,750 & 902,375 & 1 & 2 & 2.5 & 360,950 \\
\hline 4 & 992,250 & $1,250,000$ & $1,121,125$ & 1 & 3 & 3.5 & 320,321 \\
\hline 5 & $1,291,000$ & $1,518,500$ & $1,404,750$ & 1 & 4 & 4.5 & 312,167 \\
\hline 6 & $1,676,000$ & $2,476,000$ & $2,076,000$ & 3 & 5 & 6.5 & 319,385 \\
\hline 7 & $2,645,000$ & $3,410,000$ & $3,027,500$ & 3 & 5 & 6.5 & 465,769 \\
\hline 8 & $3,616,500$ & $4,525,000$ & $4,070,750$ & 3 & 6 & 7.5 & 542,767 \\
\hline 9 & $5,255,000$ & $5,383,000$ & $5,319,000$ & 3 & 7 & 8.5 & 625,765 \\
\hline 10 & $7,717,500$ & $9,037,000$ & $8,377,250$ & 7 & 11 & 14.5 & 577,741 \\
\hline 11 & $9,050,000$ & $9,050,000$ & $9,050,000$ & 6 & 12 & 15 & 603,333 \\
\hline
\end{tabular}

dari usulan tersebut, maka didapatkan tarif yang diusulkan sebagai berikut :

Tabel 9.Usulan harga berdasarkan Louvain clustering

\begin{tabular}{|c|c|c|}
\hline Kelas & Range jarak & Tarif perhari \\
\hline 1 & $0-92 \mathrm{~km}$ & 300,167 \\
\hline 2 & $92-132 \mathrm{Km}$ & 360,950 \\
\hline 3 & $132-161 \mathrm{~km}$ & 320,321 \\
\hline 4 & $161-198 \mathrm{~km}$ & 312,167 \\
\hline 5 & $199-214$ & 319,385 \\
\hline 6 & $214-272$ & 465,769 \\
\hline 7 & $272-502$ & 542,767 \\
\hline 8 & $502-583$ & 625,765 \\
\hline 9 & $583-840$ & 577,741 \\
\hline 10 & $840-1180$ & 603,333 \\
\hline 11 & Diatas 1180 & \\
\hline
\end{tabular}

Berdasarkan analisa diatas dapat dilihat cluster yang terbentuk lovian memiliki bias pada kelas 10 11. Hal ini bisa jadi karena sebaran data yang tidak sama antar kelompok. Data dengan kelas yang terbentuk terlalu sedikit namun memiliki jarak yang jauh. Oleh karen itu dalam penelitian ini lebih diusulkan dengan menggunakan metode clustering k mean, dengan sebaran data yang relatif normal. Metode lovian memiliki sebaran data yang tidak seimbang. 


\section{Kesimpulan dan SARAN}

Dari hasil penelitian dapat disimpulkan bahwa pemanfaatan data transaksi dapat digunakan untuk membentuk clustering kelas tarif dengan mempertimbangkan jarak dan biaya beban dalam tiap transaksi. Dari hasil eksperimen pengolahan data ditemukan kejanggalan sebaran data yang tidak semestinya. Kejanggalan data ini di antaranya :

1. Untuk jarak tempuh yang sama, biaya pengeluaran yang dikeluarkan tidak sama. Hal ini disebabkan pengeluaran bahan bakar yang menjadi biaya operasional terbesar tidak selalu sama. Bahan bakar yang tersisa pada tangki pada perjalanan sebelumnya yang tidak habis, sehingga terakumulasi pada penggunaan setelahnya. Ini mengakibatkan pengeluaran bahan bakar menjadi lebih sedikit dari pada seharusnya.

2. Terdapat order yang tidak sesuai antara pemasukan dan biaya pengeluaran. Order yang dilakukan adalah perjalanan dalam menghadiri kegiatan internal perusahaan, yang biaya pemasukan adalah nol rupiah, namun ongkos operasional yakni biaya bahan bakar tetap dimasukkan ke dalam data pengeluaran. Hal ini juga menyebabkan pola sebaran yang prematur.

Untuk mengatasi kejanggalan sebaran data tersebut, maka penulis menyarankan kepada pemilik usaha untuk melakukan kalibrasi kembali sisa bahan bakar yang masih tersedia dalam tangki sebelum melakukan perjalanan selanjutnya, agar menjadi pengurang biaya bahan bakar. Dalam melakukan perjalanan yang bersifat pribadi, yang tidak terdapat biaya pemasukan dan pengeluaran agar tidak di masukkan kedalam pencatatan data. Hal ini agar menjadikan data clustering dalam proses iterasi selanjutnya menjadi lebih reliable dengan tujuan akhir prediksi tarif yang lebih akurat.

Dari tabel penentuan tarif terdapat ketidaknormalan kelas yang dihasilkan dari model lovain. Hal ini bisa jadi disebabkan pada kelas 10 atau kelas atas, jumlah datanya sedikit boleh jadi masuk kedalam kelompok sebelumnya, dan tidak terbentuk kelompok baru. Sehingga kelas yang dihasilkan bias. Untuk itu dalam penelitian ini diusulkan menggunakan metode $\mathrm{K}$-means dengan sebaran tiap kelas lebih normal tidak terjadi data yang tidak seimbang. 


\section{REFERENCES}

[1] Kementerian Perhubungan nomor 108 tahun 2017, Tentang Penyelenggaraan Angkutaan Orang Dengan Kendaraan Bermotor Umum Tidak Dalam Trayek.

[2] Surat Keputusan Menteri Perhubungan Darat, Pos, Telekomunikasi dan Pariwisata Nomor L. 25/1/18/1963 tanggal 17 Juni 1963.

[3] Blue Bird Sasar Peluang Bisnis Bus Wisata, data diperolehmelalui situs internet: https://www.arah.com/article/26999/blue-bird-sasar-peluang-bisnis-bus-wisata.html

[4] Andrew B. Osmond., Suhono Harso Supangkat., Platform dan Pemodelan Kerjasama Multi Agen untuk Layanan Pengiriman Barang, Jurnal Sistem Cerdas 2019 Volume 02 No. 01, 2019, 22-24.

[5] Blondel, V. D., Guillaume, J. L., Lambiotte, R., dan Lefebvre, E. (2008) : : Fast unfolding of communities in large networks, Journal of Statistical Mechanics: Theory and Experiment, 2008(10), 1-12.

[6] McCall, M. R., Mehta, T., Leathers, C. W., dan Foster, D. M. (2002): An Efficient kMeans Clustering Algorithm: Analysis and Implementation, IEEE Transactions on Pattern Analysis and Machine Intelligence, 24, 881-892. 